\title{
Interface Phenomena on Conducting Polymer Films Investigated with Atomic Force Spectroscopy
}

\author{
Fábio L. Leite ${ }^{1,2}$, Carlos E. Borato ${ }^{1,2}$, Osvaldo N. Oliveira Jr. ${ }^{3}$, Paulo S. de Paula Herrmann ${ }^{2}$, Marcelo L. Simões ${ }^{1,2}$, \\ Ladislau Martin Neto ${ }^{2}$, Luiz H. C. Mattoso ${ }^{2 *}$ \\ ${ }^{1}$ Interunidades em Ciência e Engenharia de Materiais USP, CP 369, 13 560-970, São Carlos, SP, Brazil \\ ${ }^{2}$ Embrapa Instrumentação Agropecuária, CP 741, 13 560-970, São Carlos, SP, Brazil \\ ${ }^{3}$ Instituto de Física de São Carlos USP, CP 369, 13 560-970, São Carlos, SP, Brazil \\ *mattoso@cnpdia.embrapa.br
}

\begin{abstract}
Adsorbed layers of poly(o-ethoxyaniline) (POEA) produced with the layer-by-layer technique have been studied with atomic force spectroscopy (AFS). The films were prepared under different conditions ( $\mathrm{pH}$ and solution concentration), and measurements were carried out in air and in a liquid cell. Both the doping level and fabrication conditions affect the POEA film morphology and the interactions of the atomic force microscopy (AFM) tip with the polymer molecules. For example, a mapping of the forces indicates the presence of conducting islands surrounded by a less conductive matrix in POEA and PANI films, with the conducting islands being characterized by the presence of double-layer forces. The conducting islands are further visualized via Transmission Electron Microscopy (TEM) pictures. At pH 5, POEA appears completely dedoped where PANI can preserve some of its conducting character, and this is confirmed in electron paramagnetic resonance (EPR) measurements.
\end{abstract}

\section{INTRODUCTION}

Understanding interface phenomena in nanostructured films is important not only for the sake of surface sciences but also for technological applications. For instance, highly sensitive taste sensors have been obtained with nanostructured organic films deposited onto interdigitated electrodes, using impedance spectroscopy as the principle of detection [1], whose performance is governed by surface forces. Therefore, measurements of interactions between surfaces bearing polyelectrolyte layers can provide insights into the mechanisms responsible for detection of trace amounts of substances in waters and other liquids. Particularly suitable for studying these interactions is the atomic force spectroscopy (AFS) [2]. With AFS one can obtain images and maps of adhesion forces for polymers and organic materials coating any type of substrate. This prompted us to choose it as characterization method for studies of polyanilines (PANI) and derivatives. Interest in polyanilines arises from their high electrical conductivity in doped phases. In order to increase the processibility, the parent PANI has been functionalized in a number of ways, e.g. by substituting groups in the monomer or the polymeric backbone [3]. In this context, substituted polyanilines have been synthesized, which include poly(otoluidine) (POT), poly(o-methoxyaniline) (POMA) and poly(o-ethoxyaniline) (POEA) [4]. In particular, POEA is highly processible and displays a distinct crystalline structure [5] due to the localization of electrons in the polymer chain.

The main aim of this work is to identify conducting regions in POEA films, as the micro-level structure of POEA is believed to consist of conducting crystalline islands embedded in a nonconductive amorphous matrix, similarly to PANI $[6,7]$.

\section{EXPERIMENTAL}

POEA and PANI were synthesized according to the procedures described by Mattoso et al [8]. Layer-by-layer films (LBL) were deposited onto glass substrates covered by a chrome layer. The POEA solution was prepared in ultra pure water at a concentration of $1 \times 10^{-3} \mathrm{~mol} / \mathrm{L}$ under continuous stirring for $18 \mathrm{~h}$, and the $\mathrm{pH}$ was adjusted to 5.0 by adding $\mathrm{NH}_{4} \mathrm{OH}$. Using this solution 31-layer LBL films were produced by immersion of the substrate into POEA solution for 10 minutes for each layer. After each adsorption process, the substrate + film system was rinsed with a $\mathrm{NH}_{4} \mathrm{OH}$ solution, $\mathrm{pH} 5.0$, and then dried under room conditions. An atomic force microscope [9] TMX 2010 model SPM instrument, including special cantilevers with $\mathrm{Si}_{3} \mathrm{~N}_{4}(0,032$ $\mathrm{N} / \mathrm{m}$ ) tips and a fluid closed-cell attached to the AFM, was used to characterize the POEA film surfaces. Results from electron paramagnetic resonance (EPR) spectroscopy were obtained with a Bruker EMX-300 model. All samples were analyzed under identical conditions: $5 \mathrm{~mW}$ microwave power, $0.1 \mathrm{mT}$ modulation amplitude, microwave frequency of 9.49 $\mathrm{GHz}$, and conversion time of $20 \mathrm{~ns}$.

\section{RESULTS AND DISCUSSIONS}

The conformation of POEA in nanostructured films depends on several parameters, especially the $\mathrm{pH}$ with which the film was prepared for measurements in air, or on the solution $\mathrm{pH}$ for measurements in a liquid cell. At lower pHs, the POEA chains are more extended due to repulsion between the positively charged segments of the polymer backbone [10]. The degree of doping also affects the force curves, and this may serve to investigate the state of doping through adhesion maps. Leite et al. [12] have shown that force curves on POEA 
in contact with aqueous solutions of $\mathrm{pH} \geq 5$ display only attractive forces since there is no double-layer as POEA is non-protonated. For pHs between 4 and 5 POEA becomes doped and the repulsive force from the double-layer counterbalances the van der Waals forces. For $\mathrm{pH}=3$, where POEA is almost completely charged, the double-layer force dominates. A similar behavior should be expected for PANI, and indeed Figure 1 shows force curves with predominance of van der Waals, attractive forces at high $\mathrm{pH}$ and double-layer forces at $\mathrm{pH}$ 3. This double-layer is probably due to charges arising from a small degree of oxidation of the $\mathrm{Si}_{3} \mathrm{~N}_{4}$ tip. However, at $\mathrm{pH} 5$ there is still some repulsive force, which means that in PANI doping can be preserved at a higher $\mathrm{pH}$ than for POEA.

\section{I $0.2 \mathrm{~nm}$}

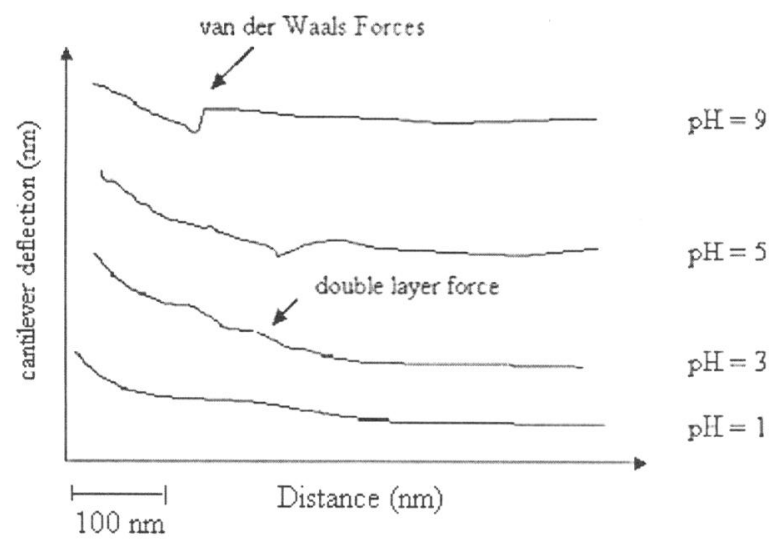

Figure 1. Force curves for a PANI film $v s \mathrm{pH}$ of the solution, in a liquid cell.

This result was confirmed with EPR results shown in Fig. 2. The peak-to-peak linewidth $\left(\Delta \mathrm{H}_{\mathrm{pp}}\right)$ of PANI is narrower than that of POEA, which means greater polaron mobility that may be associated with $\pi$-system defects [13]. The higher polaron mobility of PANI indicates a more ordered structure or higher conjugation length. The unpaired electrons of PANI have more metallic character than POEA at $\mathrm{pH}$ 5, which leads to higher conductivity [14]. Two types of paramagnetic centers are formed in POEA, polarons localized on chains in amorphous polymer regions and polarons moving along and between polymer chains. The number of the latter increases during polymer doping. After the percolation border the interaction between spin charge carriers and their mobility increases, so part of the mobile polarons collapses into diamagnetic bipolarons. This process is modulated by macromolecular dynamics, and is accompanied by an increase in the crystalline order (or dimensionality) and planarity of the system. The intensity of the EPR signal in POEA is relatively higher than in PANI which suggest higher polaron concentration in POEA. The relative polaron concentration is calculated by double integration of the spectra.

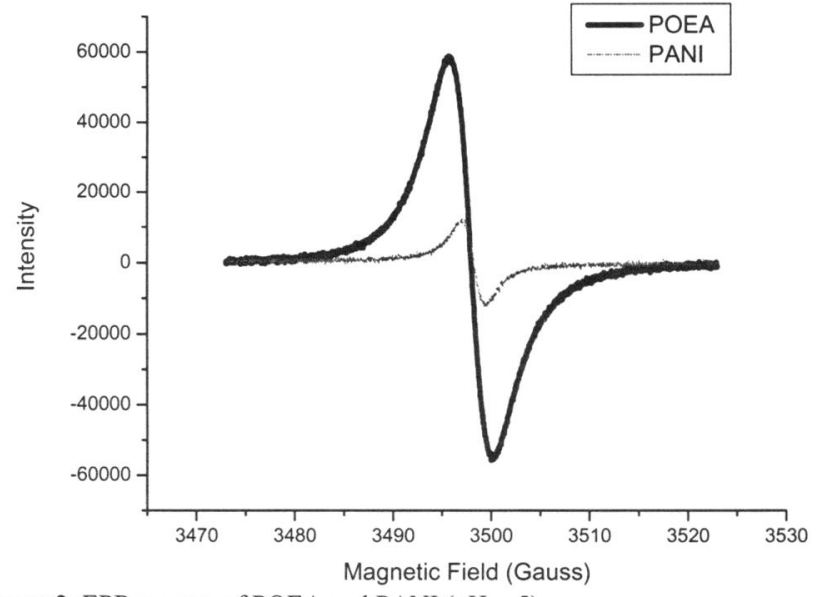

Figure 2. EPR spectra of POEA and PANI $(\mathrm{pH}=5)$.

Fig. 3 shows TEM pictures for POEA, from which one can see major differences for samples with distinct pHs. Fig. 3a shows a film with globular formation (small spheres), while Fig.3b has the appearance of small black islands (diameter: $5.2-11.5$ $\mathrm{nm}$ ) in a less dense matrix. The structure of most conductive samples corresponds to the "conductive islands" - structure suggested by Epstein et al. The inter-particle distance of the spots is in range of 1.9-6.2 nm, with average of ca. $4.0 \mathrm{~nm}$.

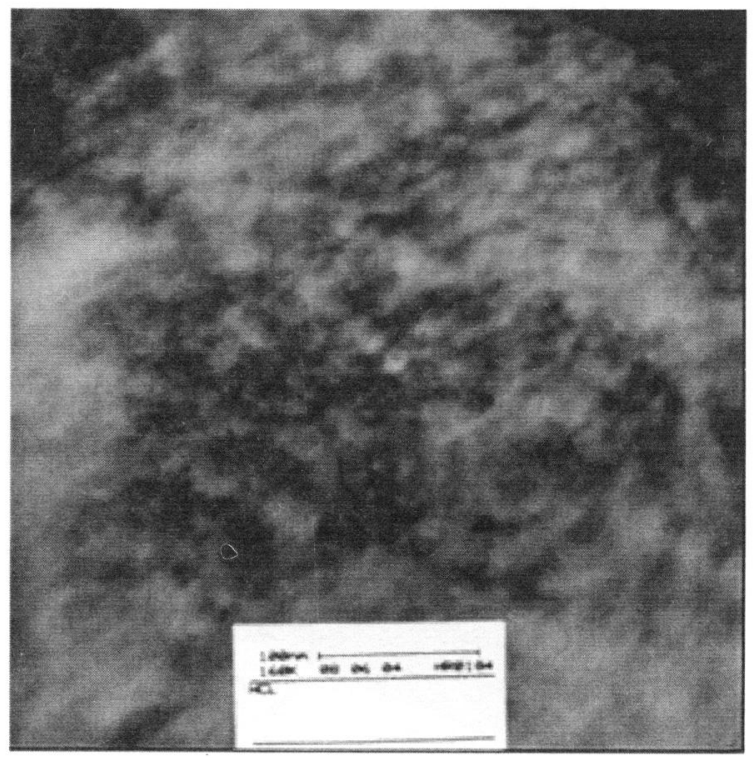

(a) 


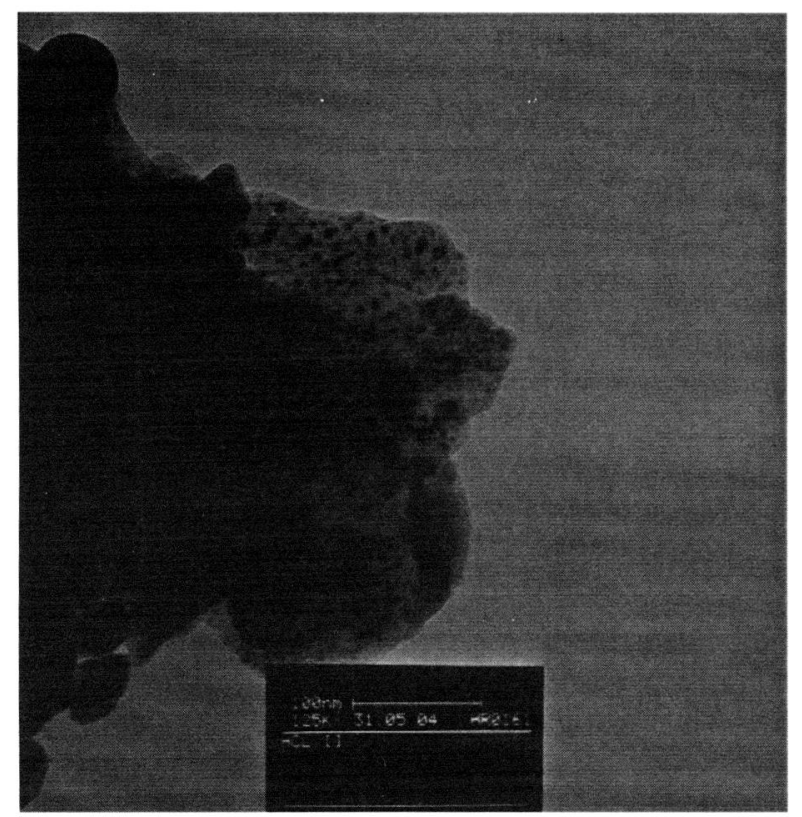

(b)

Figure 3. TEM micrograph of (a) POEA dedoped $(\mathrm{pH}=7)(\mathrm{x} 160 \mathrm{k})$ and $(\mathrm{b})$ highly doped $(\mathrm{pH}=3)(\mathrm{x} 125 \mathrm{k})$.

The formation of "conducting islands", which would be represented by the black spots in figure $3 \mathrm{~b}$ is corroborated by the adhesion maps of Figure 4 obtained with POEA films in a liquid cell. For $\mathrm{pH} \mathrm{3,} \mathrm{Fig.} \mathrm{4a} \mathrm{shows} \mathrm{islands} \mathrm{with} \mathrm{an} \mathrm{average}$ diameter of $15 \mathrm{~nm}$ in which strong double-layer effects are seen, and that would be due to repulsion between the tip and the charged substrate. In Fig. $4 b$, there are practically no islands as the $\mathrm{pH}$ at which the POEA sample is immersed in a pH 7 solution. Indeed, there are only attractive, van der Waals and hydrophobic forces.

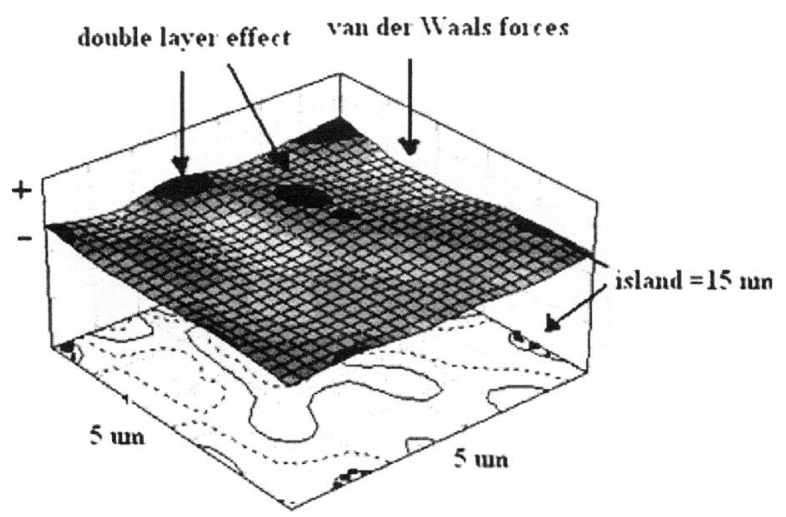

(a)

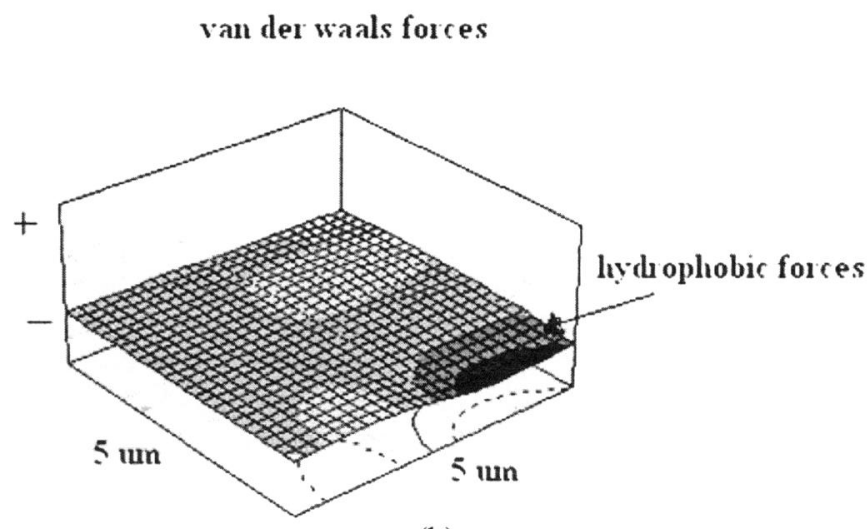

(b)

Figure 4. (a) Map of adhesion obtained by force spectroscopy showing regions of repulsive and attractive interactions on POEA films in solution $(\mathrm{pH}=3)$; (b) Map of adhesion for POEA in solution ( $\mathrm{pH}=7)$, absence of double layer forces;

One should remark that the conducting islands can only be identified with the adhesion maps. If one tries to visualize them using AFM in the contact mode, for instance, much larger aggregates are seen, as shown in Figure 5 for both pHs. The latter images were taken with the POEA sample in a liquid cell with pHs 3 and 7 for Figures $5 \mathrm{a}$ and 5b, respectively. The aggregates are larger for the low $\mathrm{pH}$, reaching $200 \mathrm{~nm}$ in diameter. Needless to say, those aggregates do not result from double-layer effects as in the contact mode one measures the strong, repulsive interaction arising from the Pauli exclusion principle. The aggregates are not the conducting islands, and may have an artificially large size due to AFM tip convolution effects.

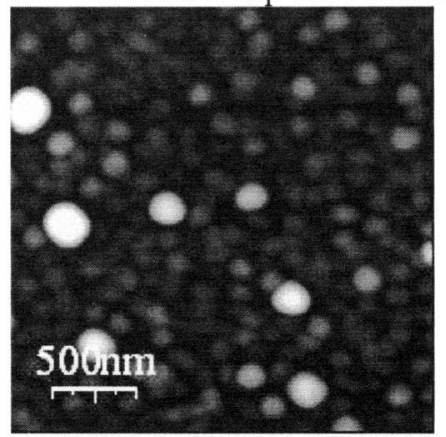

(a)

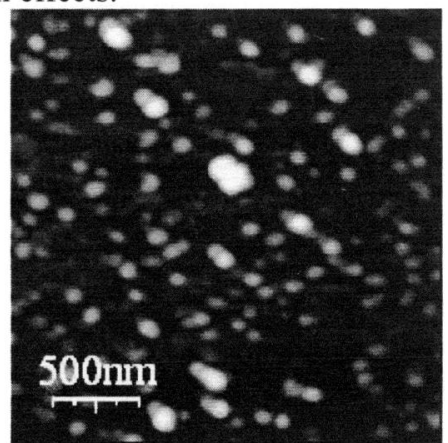

(b)
Figure 5. (a) AFM image of POEA on muscovite mica in $\mathrm{pH}=3$ and (b) AFM image of POEA in $\mathrm{pH}=7$.

\section{ACKNOWLEDGMENTS}

This work was supported by FAPESP and CNPq (network of nanobiotechnology and CT-Hidro).

\section{REFERENCES}

[1] Riul Jr, A., Gallardo Soto, A. M., Mello, Boné, S. V., S., Taylor, D. M., Mattoso, L. H. C.. Synthetic Metals 2003, 132, 109.

[2] Decher, G., Science 1997, 277, 1232.

[3] Wei, Y., Hariharan R., Patel, S. A., Macromolecules 1990, 23,758 . 
[4] Choia, H. J., Kima, J. W., Tob, K., Polymer 1999, 40, 2163.

[5] Pouget J. P., Zhao S. L., Wang Z. H., Oblakowski Z., Epstein A. J., Manohar S. K., Weisinger J. M., MacDiarmid A. G., Hsu CH., Synth. Met. 1993, 55, 341.

[6] Pouget, J. P., Josefowicz, M. E., Epstein A. J., Tang, X., MacDiarmid, A. G., Macromolecules, 1991, 24, 779.

[7] Mizoguchi, K., Nechtshein M., Travers, J.-P., Synth. Met. 1991, 41-43, 113.

[8] Mattoso, L. H. C., Manobar, S. K., MarcDiarmid, A. G., Epstein, A. J., J. Polym. Sci. A 1995, 33, 122 and Mattoso, L. H. C.; Faria, R. M.; Bulhões, L. O. S.; MacDiarmid, A. G., Polym. Sci., Polym. Chem. Ed. 32 (1994) 2147.

[9] Jalili N., Laxminarayana K., Mecatronics 2004, 14, 907.

[10] Ray A., Richter A. F., MacDiarmid A. G., Epstein A. J., Synth. Met. 29, E151 (1989)

[11] Ji, H., Hone D., Pincus P. A., Rossi G., Macromolecules 23, 698-707 (1990)

[12] Leite F. L., Borato, C. E., Herrmann, P. S. P., Oliveira, O. N., Mattoso, L. H. C. submitted to Langmuir (2005).

[13] MacDiarmid A. G., Chiang J. C., Huang W. S., Humphrey B. D., Somasiri N. L. D., 1985, 125, 309.

[14] Srinivasan D., Natarajan T. S., Rangarajan G., Bhat S. V., Wessling B., Solid State Commun. 1999, 110, 503.

[15] Zou, F., Angelopoulos, M., MacDiarmid, A. G., Epstein, A. J., Phys. Rev. B 1987, 36, 3475. 